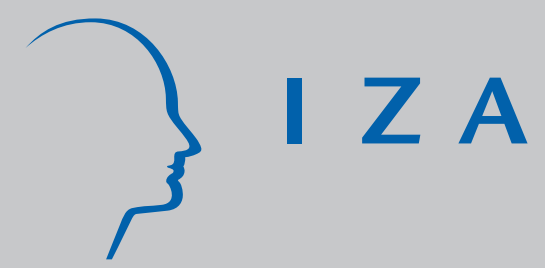

IZA DP No. 9243

Performance Measurement and Incentive Intensity

Alberto Bayo-Moriones

Jose E. Galdon-Sanchez

Sara Martinez-de-Morentin

July 2015 


\title{
Performance Measurement and Incentive Intensity
}

\author{
Alberto Bayo-Moriones \\ Universidad Publica de Navarra \\ Jose E. Galdon-Sanchez \\ Universidad Publica de Navarra \\ and IZA
}

\author{
Sara Martinez-de-Morentin \\ Universidad Publica de Navarra
}

Discussion Paper No. 9243

July 2015

IZA

P.O. Box 7240

53072 Bonn

Germany

Phone: +49-228-3894-0

Fax: +49-228-3894-180

E-mail: iza@iza.org

\begin{abstract}
Any opinions expressed here are those of the author(s) and not those of IZA. Research published in this series may include views on policy, but the institute itself takes no institutional policy positions. The IZA research network is committed to the IZA Guiding Principles of Research Integrity.

The Institute for the Study of Labor (IZA) in Bonn is a local and virtual international research center and a place of communication between science, politics and business. IZA is an independent nonprofit organization supported by Deutsche Post Foundation. The center is associated with the University of Bonn and offers a stimulating research environment through its international network, workshops and conferences, data service, project support, research visits and doctoral program. IZA engages in (i) original and internationally competitive research in all fields of labor economics, (ii) development of policy concepts, and (iii) dissemination of research results and concepts to the interested public.
\end{abstract}

IZA Discussion Papers often represent preliminary work and are circulated to encourage discussion. Citation of such a paper should account for its provisional character. A revised version may be available directly from the author. 
IZA Discussion Paper No. 9243

July 2015

\section{ABSTRACT}

\section{Performance Measurement and Incentive Intensity ${ }^{1}$}

This study addresses the factors that determine the intensity of pay for performance schemes. The results indicate that the use of individual and group incentives boost intensity, whereas plant or firm pay for performance do not seem to affect the variable of interest. In addition, the adoption of measures of results, such as productivity or quality, has a significant positive effect on intensity. On the contrary, measures of human resource management outcomes, subjective measures and financial measures are not significant or have a negative effect on the intensity of pay for performance.

JEL Classification: J30, M52, M12

Keywords: pay for performance

Corresponding author:

Jose E. Galdon-Sanchez

Department of Economics

Universidad Publica de Navarra

Campus de Arrosadia

Pamplona 31006

Spain

E-mail: jose.galdon@unavarra.es

\footnotetext{
1 The authors would like to thank the Fundacion BBVA for funding survey conducted at Spanish establishments. Alberto Bayo-Moriones acknowledges financial support from the Ministerio de Educacion y Ciencia (project ECO2013-48496-C4-2R). Jose Enrique Galdon-Sanchez and Sara Martinez-de-Morentin also acknowledge financial support from the Ministerio de Educacion y Ciencia (project ECO2011-24304).
} 


\section{Introduction}

Performance measurement is a key issue both in the basic agency model and in subsequent theoretical extensions (for a review of theoretical work see, for example, Gibbons and Waldman, 1999; Prendergast, 1999; or Raith, 2008). More specifically, incentive theory establishes that the optimal intensity of incentives (that is, the proportion that variable pay represents in total compensation) depends on the properties of performance measures. For example, a body of research concludes that the design of incentives should be based on the informativeness principle. According to this principle any (costless) measure that adds information about workers' effort should be used in compensation contracts ${ }^{1}$.

In the last few years, empirical work has addressed the influence of performance measurement on incentive intensity (see Zenger and Marshall, 2000; Bowens and Van Lent, 2006; Gibbs et al., 2009; Kauhanen and Napari, 2012, among others). Despite the advances made by these recent studies, empirical work on this issue is still scarce, and much remains to be learned about how the decision to implement low or high powered incentives is made. Consequently, it is still not clear how organizations actually design their incentive schemes. In addition, the way incentives are implemented does not always match the theoretical predictions, as occurs with the informativeness principle previously mentioned (see Raith, 2008).

One of the main difficulties faced by the study on the determinants of incentive intensity is the lack of comprehensive data on how organizations actually design their incentive systems. As a consequence, work on the topic present certain limitations. For example, some authors include the number of performance measures as a determinant of intensity, but they do not consider the influence of specific measures and their properties (see Zenger and Marshall, 2000). Others take into account only certain properties of performance measures, such as risk and distortion (see Bowens and Van Lent, 2006). Certain analyses focus on the examination of case studies (see for example Gibbs et al., 2009), while others do not make in-depth studies of the implications of performance measurement for incentive intensity. For example, Kauhanen and Napari (2012) have extensive information about performance measures and measurement levels, but they only focus on the descriptive analysis of such information.

Our aim here is to complement this empirical research and examine the influence that performance measurement exerts on the intensity of incentives. In order to do so, we address two specific questions. First, we examine how the measurement level influences incentive intensity. The choice of the measurement level 
is one of the relevant dimensions employers have to consider when designing their incentive schemes (see Baker, 2002). As Zenger and Marshall (2000) suggest, individual and collective incentives have different properties in terms of noise, distortion, and other attributes. For example, the adoption of group or plant incentives could help to solve potential problems such as distorted behavior by the worker. Consequently, we expect to find differences in the intensity of incentives depending on the organizational level of performance measurement.

Second, we take into account a broad set of measures and examine their influence on intensity for individual incentives, group incentives, and plant or firm incentives. Many studies on the topic analyze more vague categories such as financial and non-financial measures (see Ittner and Larcker, 2002). In this work, our main aim is to consider a set of indicators that comprehensively represents the measurement options available to employers. We think that our group of measures captures the specific attributes of the measurement process with precision. Consequently, we are able to carry out a detailed analysis of the determinants of incentive intensity. As we have already mentioned, we perform this analysis for the three different measurement levels available to organizations: individual group and plant or firm. We are not aware of previous work that analyses the relationship between performance measurement and incentive intensity in such an exhaustive way. Since the design of incentives at different levels may be driven by different forces, we go a step further in the study of the practice and examine the determinants of incentive intensity from a comprehensive perspective.

The analysis is based on a unique data set that contains extensive information on the provision of incentives in manufacturing establishments. More specifically, it includes data about the use of pay for performance (from now on, PfP), and about the use of PfP measured at individual (Individual PfP), group (Group PfP) and plant or firm (Plant or Firm PfP) levels. Regarding incentive intensity, the data reports on the proportion of total pay that depends on performance for each PfP scheme. In addition, it specifies which measures are used to determine performance, and contain information about a set of 11 indicators. To our knowledge, our data set constitutes a unique source of information about the relationship between PfP intensity and the use of performance measures at the three broad levels at which PfP can be implemented.

In order to study this relationship, our empirical strategy is as follows. First, we classify performance measures into four categories: Results Category, human resource management (HRM) Outcomes Category, 
Subjective Category and Financial Category. Then, we characterize each category in terms of five properties: Noise, Controllable Risk, Impact on Firm Value, Distortion and Manipulability. In addition, we describe the properties of Individual PfP, Group PfP and Plant or Firm PfP. Once we have completed our characterization of performance measures and PfP schemes, we perform OLS regressions of the determinants of incentive intensity.

Our findings show that results measures are the most common indicators of performance. In our sample, the intensity of incentives increases with the use of Individual PfP and Group PfP. On the contrary, there is no significant effect of Plant or Firm PfP use on the variable of interest. The use of the Results Category also has a positive effect on the intensity of incentives.

The remainder of the paper is organized as follows. Section 2 describes the factors that, according to the theory, determine the intensity of incentives. Section 3 deals with the level of performance measurement and its relationship with intensity. In Section 4, we analyze the indicators used to measure performance and their properties. The next section describes the data set used in this study, and Section 6 presents the results of the empirical analysis. In the last section we draw some conclusions.

\section{The determinants of incentive intensity}

From the literature on incentive provision and performance measure properties, we compile a set of factors that may influence incentive intensity. We begin by examining the agency model, which is the classic framework for understanding the provision of incentives in organizations (see Gibbons and Waldman, 1999). The central point of this model is the tradeoff between risk and incentives. The maximization problem for determining the optimal bonus rate concludes that intensity is negatively related to the agent's risk aversion, to the uncertainty in the production process and to the rate at which the marginal cost of effort increases. This framework reveals a relevant influence on incentive intensity for the purposes of our study: noise. When noise is high, the principal should increase wages to compensate workers for the risk they are exposed to (see Prendergast, 1999). From these ideas, we identify noise as the first relevant determinant of incentive intensity. More precisely, agency theory predicts a decrease of incentive intensity when noise in the production process is high.

The recent literature on incentive intensity makes a distinction between uncontrollable and controllable risk 
(see Gibbs et al., 2009 and Kauhanen and Napari, 2012; among others). On the one hand, uncontrollable risk refers to noise, that is, those environmental factors that workers are unable to control. On the other hand, controllable risk refers to the actions a worker can take to respond to risk, which depend on the worker's specific knowledge or her private information (see Kauhanen and Napari, 2012). In other words, this factor alludes to the extent workers can respond to uncertainty (see Gibbs et al., 2009). The relevance of distinguishing between the two types of risk lies in their influence on incentive intensity. In the presence of controllable risk, incentives are useful because they motivate workers to use their private information when changes in the environment occur. Therefore, controllable risk should foster incentive intensity in order to enhance workers to act in the organization's best interest.

Another extension to the basic agency model that is useful for the purposes of our analysis is that proposed by Baker (1992). This author pointed out the difference between the worker's measured performance and the worker's total contribution to firm value, which are assumed to be the same in the baseline model. According to this model, if measured performance is highly correlated with firm value, the principal should set strong incentives (high intensity). On the contrary, a low association between measured performance and organizational value renders low incentives optimal. Consequently, the link between measured performance and firm value should be a relevant determinant of incentive intensity. For example, the connection between workers' performance and firm value varies between jobs, since certain positions have a higher impact on organizational value than others. Ortin-Angel and Salas-Fumas (1998) show that this impact becomes less straightforward as we move down the organizational hierarchy, decreasing from top executives to middle managers. Hence, the intensity of incentives should be higher for those jobs whose performance has a high influence on firm value.

The literature on incentive provision also makes reference to the idea of distortion (see Kauhanen and Napari, 2012) or dysfunctional behavior (Prendergast, 1999). The problem of distortion emerges when the principal rewards the wrong behavior (see Holmstrom and Milgrom, 1991; Baker, 1992). This problem is particularly prevalent when multitasking is present, leading agents to focus on some tasks more than on others. For example, rewarding volume may incentivize workers to put relevant dimensions of performance, such as quality or cooperation with other workers, aside. As Baker et al. (1994) pointed out, "firms get what they pay for". Consequently, incentives should be carefully designed in order to limit the occurrence of 
dysfunctional behavior. Regarding the size of variable pay, the possibility of distortion should diminish intensity.

Finally, incentive provision may suffer from a problem of manipulation of performance measures. This problem emerges when workers scam the incentive scheme, increasing their performance ratings without improving organizational value (see Gibbs et al., 2009). For example, they can manipulate performance standards concerning production time or volume. Due to the presence of information asymmetries, it might be difficult for the principal to verify these standards and set optimal incentives. Manipulation could also occur when subjective measures of performance are used in incentive schemes. In this case, the agent may bias the measurement process, thus earning the favor of the superior (see Prendergast, 1999). Consequently, potential manipulability should be negatively correlated with incentive intensity. Table 1 summarizes the effects of all the factors described on the intensity of incentives.

\section{[TABLE 1 HERE]}

\section{The Organizational Level of Performance Measurement}

A necessary condition for the use of pay for performance is the existence of measured performance (see Prendergast, 1999). Therefore, one of the first issues organizations face when designing compensation schemes concerns the measurement level (see Baker, 2002). In some cases, output is easily measured in individual terms, which enhances the use of schemes that reward individual performance. When performance measurement at the individual level is difficult or costly, collective measures may be used. As Zenger and Marshall (2000) point out, the adoption of collective incentive schemes allows organizations to provide highpowered incentives when individual schemes are difficult to use. Collective incentives could help to mitigate potential problems such as distorted behavior by the worker. In addition, the combination of individual and collective incentives may bring the design of incentives closer to its optimal configuration in a firm.

In this paper, we consider the use of the three levels at which performance can be measured: Individual PfP, Group PfP, and Plant or Firm PfP. More precisely, we make an attempt to assess each of the three schemes in terms of the degree of Noise, Controllable Risk, Impact on Firm Value, Distortion and Manipulability. At this point, it is worth noticing that rating each incentive type in terms of the aforementioned factors is not an 
easy task. However, this classification is easier to construct in relative terms, that is, by describing the properties of each incentive scheme in relation to the others.

Regarding Noise, we expect that it increases with the level of performance measurement. As Zenger and Marshall (2000) point out, it is more difficult for the employee to control performance measured at high organizational levels in relation to performance determined at low levels. In collective incentive schemes, performance depends on the actions taken by all members of the group. Furthermore, collective incentives are implemented in settings where teamwork and cooperation are required (see Jirjahn, 2002). These working environments are characterized by the existence of interdependencies between workers, a wider variety of tasks and, in general, more complex and uncertain work settings. Hence, due to the complexity existing in these environments, workers are subject to risk since their compensation depends on factors they are unable to control (see Baker, 2002). Overall, the degree of uncontrollable uncertainty should increase from Individual PfP (lower Noise) to Plan or Firm PfP (higher Noise).

As we have previously mentioned, Controllable Risk should foster incentive intensity. Our intuition is that the workers' scope of action when facing uncertainty is higher if performance is measured at the individual level. On the contrary, a measure of collective performance, either at group, plant or firm level, depends on the specific knowledge and private information of multiple agents. Consequently, the set of actions an individual worker can take to respond to uncertain situations should be lower in comparison to individual incentive schemes. To sum up, we expect the degree of Controllable Risk to be higher in individual incentive schemes than in group or plant schemes.

Another relevant factor in the evaluation of the intensity of optimal incentives is the Impact on Firm Value, i.e. the impact of measured performance on the firm's goals. If this relationship is weak, incentives should be low powered (Gibbons and Waldman, 1999). Regarding the measurement level, we presume that the relationship between measured performance and the contribution to firm value increases from Individual PfP to Plant or Firm PfP. Intuitively, when aspects such as the volume of production or its quality are measured at the plant or firm level, these measures are a good representation of firm value. On the contrary, measurements of volume or quality at the individual level have a lower impact on organizational value.

As regards Distortion, the use of group incentive schemes may help to mitigate dysfunctional behavior responses. In particular, collective incentives may reduce specific problems associated with the use of 
individual measures of performance. For example, teamwork and cooperation frequently help to improve performance. However, individual rewards reduce incentives to cooperate (see Baker, 2002). This dysfunctional behavior could be alleviated if collective incentives are introduced. Similarly, the use of pay linked to plant or firm results may help to avoid distortions associated with the provision of individual incentives. Overall, our idea is that Distortion decreases from Individual PfP to Plant or Firm PfP.

Finally, we expect the problem of Manipulability of performance measures to vary with the level of measurement. This problem arises when workers take advantage of information asymmetries to increase their performance ratings without improving firm value. We anticipate that the ability of a worker to manipulate game a measure will decrease from individual incentives to collective schemes. For example, it is easier for a worker to manipulate volume standards when production is measured individually. However, if collective incentives are used, it becomes implausible that workers can game these standards, or manipulate any other dimension of performance. All these ideas concerning the determinants of incentive intensity and the measurement level are summarized in the following table.

[TABLE 2 HERE]

According to this table, Individual PfP presents good properties in terms of Noise and Controllable Risk. Plant or Firm PfP have a higher Impact on Firm Value, as well as low levels of Distortion and Manipulability. Finally, Group PfP is at the center of our ranking regarding the five properties. This characterization of PfP schemes makes it difficult to draw conclusions about their influence on intensity. Overall, Plant or Firm PfP display better properties than Individual PfP. However, it may also be true that employers give more importance to some characteristics (e.g. reducing noise problems) than others. The empirical analysis will shed more light on the relationship between the measurement level and incentive intensity.

\section{Properties of Performance Measures}

In this section, we characterize a set of performance measures in terms of their degree of Noise, Controllable Risk, Impact on Firm Value, Distortion and Manipulability. A performance measure is an indicator, either 
quantitative or qualitative, that evaluates employees' outcomes. We group performance measures into four categories: Results Category, HRM Outcomes Category, Subjective Category and Financial Category. In order to construct this classification, we draw on the work by Heneman et al. (1999). According to these authors, results measures are in an intermediate position regarding both controllability and the link with the firm's value. In relation to these measures, HRM outcomes (in the terminology used by Heneman et al., behavioral measures), have a higher motivational value because workers can control them to a great extent. On the other hand, financial measures are more closely related to the firm's value, but workers have only limited control over them. In addition to these three factors we incorporate subjective indicators (Subjective Category) in our classification. We think this category is worth considering when grouping performance measures. On the one hand, subjective measures are widely used by organizations because they help to solve the deficiencies in objective measurement, such as the presence of noise (see Bol and Smith, 2011). In addition, subjective measures display different properties from the other categories, since they involve discretion and judgment by supervisors. Hence, they should be included in an independent category when performing the empirical analysis. The Results Category includes the following measures: Productivity, Volume and Quality. The HRM Outcomes Category considers Absenteeism, Punctuality and Injuries. The Subjective Category includes Subjective Evaluation, Customer Satisfaction and External Evaluation. The Financial Category comprises Profitability and Cost Savings.

The literature on performance measurement has considered other classifications besides the one we employ in this study. Among the most frequently used we find the distinction between financial and non-financial measures, that between broad and narrow measures or between input and output measures (for a review of different classification schemes see, for example, Ittner and Larcker, 2002). However, we consider that our choice of the four different categories mentioned is a more exhaustive representation of measurement options. Instead of focusing on comparing two broad measurement schemes (financial vs. non-financial, or input vs. output) we go a step further and compare the effects on incentive intensity of four different categories of performance dimensions. Hence, we avoid the limitations associated with the use of more vague classification schemes, such as the failure to account for characteristics like the specific activities (productivity, absenteeism, customer satisfaction, etc.) that the measure accounts for (see Ittner and Larcker, 2002). In what follows, we describe the properties of each category of measures. 
Noise

Focusing on the first property, the Results Category provides some sources of Noise that should be considered when designing incentive schemes. Measures such as Productivity, Volume or Quality depend on uncontrollable factors to a certain extent. For example, they are influenced by technology. The productivity of an employee also depends on the results of colleagues or the decisions taken by superiors. On the other hand, the measures included in the HRM Outcomes Category may be beneficial to reduce potential sources of Noise in performance measurement. When incentives are based on aspects such as absenteeism, punctuality or injuries, for which a lower level of uncontrollable risk is involved, the problem of Noise becomes less prevalent.

Measures included in the Subjective Category are claimed to provide a comprehensive picture of performance (see Prendergast, 1999). Since they are based on assessments of multiple dimensions, these measures reduce Noise in the evaluation process. More precisely, one of the main reasons for using subjective measures is the risk associated with objective indicators (Baker, 1994). This idea is also tested by Bol and Smith (2011). By means of an experiment, these authors show that supervisors use subjective measures to compensate for the deficiencies in objective measurement and, in particular, to offset the negative effects caused by uncontrollable factors. Consequently, we conclude that the introduction of subjective evaluation mitigates Noise problems in incentive contracts.

Finally, measures belonging to the Financial Category, such as Profitability or Cost Savings are highly exposed to factors outside the worker's scope. As Bowens and Van Lent (2007) suggest, indicators such as profits are more dependent on exogenous factors than non-financial measures and, consequently, they are noisier. These authors state that "the primary function of disaggregated and nonfinancial measures is to reduce the noise in aggregated financial measures". For example, financial measures may be influenced by uncertainty in the environment, driven by factors such as regulatory decisions that affect competition, or by economic conditions. They also depend on the firm's decisions such as investment, on which the worker has little or no influence. The limited control of the worker hinders the motivational value of such measures (see Heneman et al. 1999), thus affecting the intensity of the optimal incentive scheme. 


\section{Controllable Risk}

Regarding Controllable Risk, Heneman et al. (1999) place the Results Category in an intermediate position in comparison with other categories. In particular, it is claimed that workers have high control over measures such as Productivity or Volume. As Ittner and Larcker (2002) point out, non-financial measures such as Productivity "are better at signalling the actions workers can take to improve overall performance and at isolating the contribution of particular workers or activities". Consequently, workers are informed about how they should behave to improve performance, and they can exert control over the actions leading to incentive increases.

As Heneman et al. (1999) also describe, employees can easily control behavioral measures. In fact, these measures are more controllable by workers than the rest of the criteria, since they can determine with precision their outcomes regarding, for example, Absenteeism or Punctuality. Overall, when employees clearly understand how their actions influence compensation, the degree of Controllable Risk increases.

Subjective evaluation commonly accounts for different dimensions of a worker's job, ranging from collaboration with other employees to the relationship with clients (see Jirjahn and Poutsma, 2013). All of these aspects are controllable by workers, so one should expect the degree of Controllable Risk to be higher in relation to other measure categories. However, the Subjective Category involves judgement and discretion by the person who performs the appraisal. Hence, there are aspects of the process workers are unable to control. Overall, we consider the Subjective Category to display a high degree of Controllable Risk, not forgetting that they may be subject to certain factors not controlled by employees.

Regarding the Financial Category, production employees hardly exert any control over measures such as Profitability or Cost Savings (we only include production workers in the analysis). Other workers, such as top managers, have higher control over these measures. This characteristic reduces the degree of Controllable Risk displayed by financial measures in relation to the results, HRM outcomes and subjective indicators.

\section{Impact on Firm Value}

Another relevant factor concerning incentive intensity is the measure of Impact on Firm Value. Looking at the Results Category, their impact is high in comparison with other performance criteria. For example, 
improvements in workers' productivity will eventually have an impact on organizational performance. However, the correlation between the two variables is not perfect, since overall performance is a global result that depends on many aspects (Heneman et al., 1999). The Results Category focuses on particular activities (such as Volume or Quality) and, consequently, they do not entirely account for all the dimensions relevant to determining global performance.

On the contrary, the contribution to firm's objectives is blurred when it comes to the HRM Outcomes Category. Despite the validity of these measures as instruments to motivate workers, they are only weakly related to organizational performance. HRM outcomes such as Punctuality or Absenteeism are very taskspecific, so they only reflect a narrow set of workers' actions. Hence, their Impact on Firm Value should be lower in comparison with other categories of indicators that represent a broader set of activities (Ittner and Larcker, 2002).

When management uses evaluation systems based on the perceptions of a supervisor, customers, or external agencies, it is difficult to interpret their ratings in terms of organisational performance. For example, there is no direct link between subjective perceptions of collaboration between employees, or the quality of relations with customers, and organisational performance. However, on many occasions supervisors are able to provide assessments that represent firm value more accurately than certain objective measures. As Baker et al. (1994) point out, when objective criteria are difficult to determine, subjective evaluations may improve the measurement of workers' contribution to firm value, even if such subjective criteria are imperfect.

The Financial Category adds a broad set of variables and actions, accounting for a variety of dimensions of a worker's performance. Consequently, it represents organizational performance more accurately than measures of results or HRM outcomes, which are narrower and more task specific as we have already described. Therefore, any incentive scheme that uses the Financial Category links compensation to the firm's value with more precision than schemes based on other type of indicators (Gibbons and Waldman, 1999).

\section{Distortion}

The presence of Distortion, that is, rewarding the wrong behavior, is also a relevant factor influencing incentive intensity (see Holmstron and Milgrom, 1991; Baker, 1992). The Results Category may enhance an undesired allocation of effort across tasks. More specifically, when workers perform various activities, they 
may put more effort into the activity that most influences their compensation. This problem is likely to arise if measures of results are used in compensation contracts. For example, when the size of incentives depends on the number of units produced by workers, they may be temped to ignore Quality. However, it is worth noticing that the problem of Distortion could be avoided or mitigated if several indicators of results are combined, so that different dimensions of performance are rewarded.

The HRM Outcomes Category also focuses on the deployment of specific tasks or activities. Consequently, it can induce distortionary behavior, leading workers to put relevant actions aside. However, we infer that the degree of Distortion is lower in comparison to the use of the Results Category. In order to support this argument, we draw from Holsmtrom and Milgrom (1991), and assume total effort is constant and should be allocated to different tasks. When activities are substitutes (such as quality and quantity), agents have to choose how to distribute effort. However, this problem is less likely to arise if activities are complementary. Hence, workers may work on improving several HHRR indicators at the same time, such as Punctuality and Absenteeism. Then, Distortion is less likely to appear.

In order to solve or mitigate distortionary behavior, the theory on incentive provision suggests the use of subjective assessments substituting or complementing objective measures (see Baker et al., 1994). The Subjective Category allows managers to account for different dimensions of a worker's job, thus limiting the focus of workers on particular actions. Hence, their inclusion in incentive schemes could reduce the problem of Distortion. Similarly, the fact that the Financial Category does not reward particular tasks leaves less scope for Distortion. As we have already mentioned, financial indicators provide aggregate measures of performance. The idea is similar to the one presented for the Subjective Category. In both cases, measures represent a broad picture of workers' performance, which avoids workers emphasizing only particular tasks.

\section{Manipulability}

Since workers possess asymmetric information about their results, they can manipulate performance standards concerning production time or volume, and it might be difficult for managers to verify these standards. Hence, the employer has to take into account that the use of incentive schemes based on the Results Category is subject to manipulation. On the other hand, the measures included in the HRM Outcomes Category are based on particular tasks. Due to the specificity of these measures, they can be easily controlled 
by a supervisor. Therefore, it is not likely that a worker can use asymmetric information to bias these dimensions of performance. Hence, we anticipate that Manipulability is not an important issue in indicators of HRM outcomes.

Despite the virtues of using subjective measures in incentive schemes, the adoption of these measures is not exempt from potential problems. Specifically, there is what Prendergast (1999) calls "rent-seeking activities". This problem concerns any actions workers can take to influence the ratings given by supervisors. In other words, workers who want to win the favor of their superiors could play with incentive schemes based on the Subjective Category. This idea supports the concept of potential manipulation by workers in subjective evaluation. Regarding the Financial Category, non-managerial workers, like blue-collar ones, have little specific potential to determine outcomes such as Profitability or Cost Savings. Consequently, we infer the degree of Manipulability of these measures is low in relation to other categories such as results and subjective measures.

Table 3 summarizes all the ideas presented below and describes the four categories of measures in terms of their degree of Noise, Controllable Risk, Impact on Firm Value, Distortion and Manipulability. In order to construct this table, and as we have previously mentioned, we focus on the comparison of each category of measures with the rest of groups. However, we think this procedure does not compromise the purposes of the study. On the contrary, our final objective is to compare the incentive intensity associated with the different alternatives of performance measurement available to employers.

\section{[TABLE 3 HERE]}

From the examination of this table, it is not easy to come to definitive conclusions about the relationship between the categories of measures we have defined and incentive intensity. Each category has its strengths and weaknesses in terms of the properties described in this study. However, one interesting conclusion can be drawn from the analysis developed in this section. With the exception of Distortion, the use of the Results Category does not display what the theory considers "bad" properties in terms of the factors that affect intensity. As we hypothesized, the levels of Noise, Controllable Risk, Impact on Firm Value, and Manipulability are all moderate for results measures. On the contrary, the HRM Outcomes, Subjective and 
Financial Categories display one or more properties that, according to theory, should lead to a low incentive intensity. Then, it is possible that the use of the Results Category promotes incentive intensity. However, it is also true that other categories present better characteristics than result measures in terms of certain properties. For example, the Financial Category has, in relative terms, a high Impact on Firm Value, and it ranks low in terms of Distortion and Manipulation. The empirical analysis will shed light on these issues.

As a final remark, one should bear in mind that incentive schemes may include several measures of a particular category. For example, Productivity may be combined with Volume or Quality measures. This is a relevant issue when analyzing incentive intensity, because some of the problems of a category of measures might be solved if several indicators are jointly implemented. According to the Informativeness Principle, a compensation contract should include all measures that provide information about workers' performance. However, it has been shown that this principle is not observed in many firms (Prendergast, 1999; Raith, 2008). In relation to this idea, Zenger and Marshall (2000) hypothesize that increasing the number of indicators in group incentives generates problems for organizations, such as an inefficient allocation of workers' effort across several tasks. In order to avoid such problems, managers might decide to decrease incentive intensity as the number of indicators increases. However, the authors do not find empirical support for this idea.

\section{Data and Variables}

The data were collected through personal interviews with managers in Spanish manufacturing plants with 50 or more employees, and represent a unique source of information about a range of human resource practices in Spanish firms. Information was gathered at the plant level, as this is the unit at which decisions about the implementation of the HRM practices of interest are taken. Furthermore, we expected knowledge of the issues included in the questionnaire to be greater at plant level and, as a consequence, believed the data obtained would be more reliable.

The process of development of the database was as follows. Once we defined the objectives and scope of our study, we conducted a thorough examination of the literature related to our purpose in order to properly design the questionnaire. With the information gathered, members of the research group and the firm in charge of the fieldwork jointly drew up a first draft of the questionnaire. We pre-tested the questionnaire in 
nine plants and then modified it in several ways to come up with the final version.

Most of the information on HRM refers exclusively to blue-collar workers, that is, workers involved directly in the production process. The reason for restricting the analysis to this category of employees is the existence of a range of different internal labor markets with different features within the same organization. Limiting the study to manual workers makes comparisons across establishments easier.

The data were drawn from personal interviews with one of the managers at the plant. We thought that questions should be addressed to the general manager or to the human resource manager. In practice we interviewed the human resource manager most frequently. The range of potential survey respondents comprised all Spanish manufacturing establishments that had 50 or more employees in 2005. After stratification by sector, size, and location, we used 2005 data from the Spanish Central Directory of Firms (Directorio Central de Empresas, DIRCE) of the Spanish National Statistics Institute (Instituto Nacional de Estadistica, INE) to make a random selection of workplaces.

The interviews with managers who agreed to respond to our questionnaire were performed by professionals with specialized training in computer-assisted telephone interviews (CATI). The establishments were first approached by letter or email, indicating the goals of the survey and including a copy of the questionnaire. We contacted a total of 2,933 establishments and this effort yielded 1,001 valid interviews. This final number of interviews matched expectations regarding the size of the data set, representing a response rate of $34.1 \%$. The data set contains exhaustive information about the use of PfP, which enables an in-depth analysis of the practice. Specifically, the questionnaire inquired about the use of general PfP, as well as about three particular schemes: Individual PfP, Group PfP, and Firm or Plant PfP. Regarding incentive intensity, the data informs on the proportion of total pay that depends on performance. In addition, it specifies the proportion of pay that depends on individual performance, on group performance, and on plant or firm performance. In additions, questionnaire respondents were asked about the use of 11 measures of performance: Productivity, Volume, Quality, Absenteeism, Punctuality, Injuries, Subjective Evaluation, Customer Satisfaction, External Evaluation, Profitability and Cost Savings. The database specifies whether each of these measures is used in Individual PfP, in Group PfP and in Plant or Firm PfP.

As we have already described, we construct a classification of measures consisting of four different categories. The Results Category includes measures of Productivity, Volume and Quality. The HRM 
Outcomes Category refers to Absenteeism, Punctuality and Injuries. The Subjective Category considers Subjective Evaluation, Customer Satisfaction and External Evaluation. The Financial Category comprises Profitability and Cost Savings.

Finally, the analysis includes a set of four controls. The first is the variable Size, which is measured as the number of employees in the establishment (see Zenger and Marshall, 2000). This variable takes a mean value of 188.01 and a standard deviation of 467.87. The second one is Age, which represents the number of years the plant has been in operation (see Heywood and Jirjahn, 2014). The mean value of Age is 44.89, and its standard deviation equals 29.37. In the regression analysis, we include the logarithms of both the Size and Age variables to avoid the influence of extreme values. Multinational is a dichotomous variable that takes value one if the firm has foreign ownership (see Heywood and Jirjahn, 2014). It takes a mean value of 0.21, and a standard deviation of 0.41 . Finally, Trade Union captures the influence of trade unions in the plant, and takes values from one (low influence) to five (high influence), (see Barth et al., 2008). The mean value of Trade Union is 2.91, and the standard deviation equals 1.15 .

\section{Results}

\section{Preliminary Analysis}

Before performing the regression analysis, we examine the incidence of PfP schemes and performance measures in detail. Regarding the use of PfP schemes, 53.15 per cent of the plants in our sample report using PfP. As for the adoption of each particular scheme, Individual PfP is the most widespread (33.57 per cent of plants), followed by Group PfP (20.58 per cent) and Plant or Firm PfP (16.18 per cent).

Table 4 shows the incidence of performance measures. The first column represents the frequency of plants that adopt each measure for at least one incentive scheme (individual, group, or plant or firm). The other three columns include frequencies for each particular scheme. In the first column, we observe that Productivity is the most widespread measure in our sample (380 plants), followed by Quality (197 plants), Volume (128 plants), and Absenteeism (101 plants). At the lower end of the classification we find Customer Satisfaction (20 plants), Cost Savings (15 plants) and External Evaluation (12 plants), which are only implemented if Plant or Firm PfP is used. 


\section{[TABLE 4 HERE]}

Regarding Individual PfP (column 2), the most common indicators of performance are Productivity (256) and Quality (121). Looking at the HHRR Outcomes Category, the use of Absenteeism predominates over the implementation of Punctuality and Injuries. Finally, Subjective Evaluation is adopted in 45 plants, that is, 13.68 per cent of establishments using Individual PfP. As far as Group PfP is concerned, the results reproduce the pattern described for individual incentives. Productivity and Quality are the preferred measures in this particular scheme, whereas Punctuality is the less widespread indicator. However, when we analyze the results for Plant or Firm PfP, some differences emerge in relation to the other two incentive schemes. This might be explained by the fact that there is a higher number of measures available to firms. Again, Productivity leads the ranking (around 50 per cent of plants), but it is used with a lower frequency compared to Individual PfP and Group PfP. The use of this measure is followed closely by Profitability (35 per cent of plants), the most common indicator of the Financial Category.

Table 5 displays the number of performance measures by incentive scheme. In the three schemes, around half of the plants in the sample use only one measure. Between 21 and 26 per cent of establishments implement two measures in their incentive schemes, and three measures are only adopted by approximately 19 per cent of plants. Eight per cent of employers make use of four different measures in Plant or Firm PfP, but this percentage is even lower in Individual PfP and Group PfP. The percentage of plants including five or more measures is almost negligible. Overall, the results in Table 5 show that, despite the variety of performance measures available, most employers base their PfP schemes on one or two measures only.

[TABLE 5 HERE]

Table 6 depicts the incidence of each category of measures. More precisely, the table shows the number and percentage of plants using at least one measure of the category. In the first column, we see that over 90 per cent of the sampled plants use the Results Category. Individual PfP and Group PfP schemes match this pattern. For Plant or Firm PfP, the percentage is lower but still noteworthy: 65 per cent of plants with this 
scheme adopt at least one results measure. The second most popular category of measures in Individual PfP and Group PfP is the HRM Outcomes Category. But the frequencies are far below those observed in the first category: 22 per cent in individual incentives and 28 in group incentives. Plant or Firm PfP displays a different picture: the use of measures in the Financial Category is more widespread than the use of measures in the HRM Outcomes Category, being used in 38 per cent of the plants. For the three PfP schemes, the measures in the Subjective Category come last, although they are more frequent in Plant or Firm PfP.

\section{[TABLE 6 HERE]}

Table 7 displays the number of categories in our sample of establishments. We observe that, for all the incentive schemes, more than 60 per cent of plants use only one category of measures. This figure is considerably high for Individual PfP, with 77.51 per cent of plants using only one category of measures. Between 17 per cent (Individual PfP) and 28 per cent (Plant of Firm PfP) of plants use two categories of measures. The use of three categories is restricted to a small percentage of organizations, ranging from 5.5 per cent to 6.5 per cent. Finally, only three per cent of the total number of plants in the sample implement measures of the four categories.

[TABLE 7 HERE]

The number of performance measures per categories is shown in Table 8. In the Results Category, a significant proportion of establishments use more than one measure (approximately 45 per cent of plants). This figure is similar for the HRM Outcomes Category, whereas it decreases significantly when it comes to the Subjective and Financial Categories. Regarding the two latter categories, more than 80 per cent of establishments use only one performance measure.

[TABLE 8 HERE] 


\section{Regression Results}

We now focus on examining the results concerning the intensity of incentives. PfP represents, on average, 18.49 per cent of total pay in our sample of plants. The intensity of PfP decreases from Individual PfP (17.36 percent of total pay) to Group PfP (16.08) and Plant or Firm PfP (11.86).

Table 9 depicts OLS estimations of the total intensity of PfP. The table presents five regression models, each including a different set of explanatory variables. The five models add the group of controls we have previously described: the size of the plant, its age, whether it belongs to a foreign company, and the influence of trade unions ${ }^{2}$. Model 1 focuses on the analysis of how the measurement level affects incentive intensity. The coefficients for both Individual PfP and Group PfP are positive and highly significant. Hence, according to our estimations, the adoption of any of these schemes promotes incentive intensity. The magnitude of the coefficient is slightly higher for Group PfP. On the contrary, the use of Plant or Firm PfP does not seem to exert any significant influence on intensity.

\section{[TABLE 9 HERE]}

Model 2 includes the 11 performance measures as explanatory variables in the estimated equation. Productivity and Cost Savings are the only measures with a positive and significant effect on the strength of incentives. On the other hand, there are four measures that display negative coefficients. In particular, two of the measures belonging to the HRM Outcomes Category exert a negative effect on PfP intensity: Absenteeism and Injuries. In addition, the use of External Evaluation as a subjective measure of performance also reduces intensity according to our estimations. Finally, Profitability emerges as a negative determinant of incentive intensity in our sample of plants.

In the third model, the regressors are the four categories of measures defined in the third section. These variables represent whether at least one measure of the category is used to determine performance. What does the empirical analysis reveal about the effect of the categories of indicators? Only the Results Category emerges as a significant predictor of incentive intensity, and it displays a positive sign. The other three categories of measures have negative coefficients, but they are not statistically significant. As we have already described, this outcome could be explained by the moderate properties of the Results Category. In 
addition, the problems associated with the use of particular measures of the Results Category can be mitigated or eliminated if other indicators with better properties are added. As Table 8 reveals, a significant proportion of establishments use more than one measure of results, whereas this frequency is lower for other categories.

In Model 4, both the three PfP schemes and the 11 performance measures are included. Regarding the measurement level, this estimation reproduces the results of Model 1: a positive and significant effect of Individual PfP and Group PfP on incentive intensity, and no significant effect of Plant or Firm PfP. Regarding the performance measures, the findings are also similar to those obtained in the second model. The main differences concern Productivity, which is no longer a significant predictor of intensity, and Subjective Evaluation, which is now negatively correlated with the variable of interest. Finally, Model 5 includes the PfP schemes and the four categories of variables. For the first set of regressors, the results are no different than the ones described in the previous models. Regarding the second set, the Results Category has a positive incidence on incentive intensity. The magnitude of this effect is, however, smaller than the one obtained in Model 2. Again, the inclusion of HHRR Outcomes, Subjective or Financial Categories does not contribute to explaining the strength of PfP.

Table 10 presents OLS estimations of incentive intensity for Individual PfP, Group PfP and Plant or Firm $P f P$. For each scheme, we estimate two regression models with a different set of predictor variables. The first contains the 11 performance measures individually, whereas the second considers categories of measures. The first model offers evidence supporting the influence of several measures on Individual PfP intensity. In particular, intensity increases when Productivity is used as an indicator of workers' performance. On the contrary, it decreases when the incentive scheme is based on Injuries or Subjective Evaluation. According to Model 2, the intensity of Individual PfP increases if at least one measure of results is implemented. On the contrary, the use of Subjective Evaluation exerts the opposite effect on the magnitude of this PfP scheme.

\section{[TABLE 10 HERE]}

The results concerning Group PfP show that our sets of regressors are limited when attempting to explain the intensity of this incentive scheme. Model 3 shows that intensity is only related to the use of Punctuality and 
Injuries. The first measure correlates positively with the dependent variable, whereas the second exerts a negative effect. The results of Model 4 are even poorer, since none of the three categories of measures for which there are observations seem to exert any influence on Group PfP intensity.

The last two models concern the intensity of Plant or Firm PfP. If we look at the influence of particular measures (Model 5), both Absenteeism and Profitability emerge as negative determinants of intensity. In contrast, Cost Savings promotes the strength of this scheme of incentives, with a coefficient of significant magnitude. Finally, Model 6 illustrates the positive impact of the Results Category on intensity, matching the results obtained for total intensity as well as Individual PfP intensity. But in contrast with these models, the use of at least one measure of the HRM Outcomes category is negatively and significantly related to Plant or Firm PfP intensity.

\section{Conclusions}

In this study, we have examined the impact of the measurement level and the measures used to determine performance on PfP intensity. In order to do so, we have analyzed both the three measurement levels and the four measure categories in terms of the five properties that the literature on incentives identifies as important determinants of intensity. The study makes use of an exhaustive data-set that contains information at the plant level about the use of 11 performance measures in three PfP schemes: Individual PfP, Group PfP, and Plant or Firm PfP. In addition, we have information on the total intensity of PfP in each plant, as well as on the intensity of the three PfP schemes. To our knowledge, our data-set constitutes a unique source of information about PfP intensity and the use of performance measures at the three broad levels at which PfP can be implemented.

The analysis of the data reveals interesting patterns of performance measurement by employers. Results measures are, by far, the most widely used in our sample of firms. More specifically, a high number of PfP schemes are based on indicators of Productivity and Quality. Profitability is also a popular measure in Plant or Firm PfP. Due to the scarcity of similar data, it is difficult to compare these results with those of other studies. For example, from the analysis of the Consortium for Alternative Reward Strategies Research data (see McAdams and Hawk 1994), Ittner and Larcker (2002) we find that 52 per cent of firms use accounting measures, 48 per cent use quality measures, and only 25 cent adopt productivity measures (each plant in the 
sample may use more than one performance measure). Using a sample of Finnish companies, Kauhanen and Napari (2012) observe that profitability is the predominant measure for blue collar workers, followed by quality and productivity. However, it is noteworthy that these studies refer to plants in various industries, and consider a mixture of schemes that cover varied organizational units, from the entire company to subsidiaries, divisions, departments, small teams, etc.

In addition, our data reveals that Individual PfP is the most common scheme, followed by Group PfP and, finally, Plant or Firm PfP. Around fifty per cent of firms use only one measure of performance in their PfP schemes, and the adoption of more than three measures is very infrequent (around 10 per cent of firms). Hence, despite the variety of indicators available, employers prefer to focus on very few criteria when designing their incentive schemes. As we have already mentioned, the most popular measures are those that belong to the Results Category. These findings suggest that the Informativeness Principle, the idea that any measure that adds information to incentive schemes should be used, is not supported by our analysis. Other studies have drawn different conclusions. For example, Kauhanen and Napari (2012) find that incentive schemes for blue-collar workers use, on average, four performance measures.

According to our estimation, the scheme that has the greatest impact on intensity is the one that does not present significant problems regarding any of the properties considered, that is, Group PfP. The adoption of Individual PfP also promotes incentive intensity. On the contrary, there is no significant effect of Plant or Firm PfP use on the intensity of incentives. These results suggest that, when designing incentive schemes, managers give more weight to those schemes that reduce Noise and display high levels of Controllable Risk (Individual PfP) versus those schemes generating Noise and reducing Controllable Risk (Plant or Firm PfP). According to theory, the effectiveness of collective PfP schemes depends on their intensity (see Zenger and Marshall, 2000). In our sample, the adoption of Plant or Firm PfP does not seem to be linked to the use of high powered incentives, so this may limit their effectiveness for increasing workers' efforts, attracting more able workers and, consequently, enhancing organizational performance. This result is also relevant because Plant or Firm PfP display good properties in terms of their Impact on Firm Value, Distortion and Manipulability.

With the exception of Group PfP, the use of at least one measure of the Results Category promotes incentive intensity in all the schemes analyzed. The remaining categories of measures are either not significant or have 
a negative effect on the magnitude of incentives. As we have already described, the Results Category displays moderate levels of Noise, Controllable Risk, Impact on Firm Value, and Manipulability. On the contrary, the HRM Outcomes, Subjective and Financial Categories present problems regarding some of the properties. A plausible interpretation of our findings is that employers choose performance measures that display, on average, good characteristics when using high-powered incentive schemes. These results are related to those obtained in Gibbs et al. (2009), who conclude that "the more than a measure is flawed along any of these dimensions (noise, controllable risk, distortion and manipulation), the less weight is given to that measure for explicit incentives".

Our study reflects certain caveats such as those inherent to the use of cross-section survey data. In addition, since most theoretical insights refer to the weights given to performance measures, it would be interesting to develop data sets containing such information. In this study, as in Kauhanen and Napari (2012), Hwang et al. (2009), and Ittner and Larcker (2002), we only observe whether a measure is used or not in an incentive scheme. Another limitation of this work is that we have developed our own characterization of measurement levels and categories of measures, but we cannot directly determine their properties. Despite these limitations, our results support the idea that the intensity of PfP is significantly related to the way performance is measured. We hope this work serves to launch further empirical research on the topic, and to develop new theoretical insights on the relationship between performance measurement and incentive intensity. 


\section{Notes}

1. For a more detailed description of the Informativeness Principle, see Holmstrom (1979).

2. The results of the control variables are not displayed in the table, but they are available from the authors upon request. 


\section{References}

Baker, George P. 1992. “Incentive Contracts and Performance Measurement.” Journal of Political Economy 100(3): 598-614.

Baker, George P. 2002. "Distortion and Risk in Optimal Incentive Contracts." The Journal of Human Resources 37(4): 728-751.

Baker, George P., Robert Gibbons and Kevin J. Murphy. 1994. "Subjective Performance Measures in Optimal Incentive Contracts." Quarterly Journal of Economics 109: 881-919.

Barth, Erling, Bernt Bratsberg, Torbjørn Hægeland, and Oddbjørn Raaum. 2008. "Who Pays for Performance?" International Journal of Manpower 29(1): 8-29.

Bol, Jasmijn C., and Steven D. Smith. 2011. "Spillover Effects in Subjective Performance Evaluation: Bias and the Asymmetric Influence of Controllability.” Accounting Review 86(4): 1213-1230.

Bowens, Jans and Laurence Van Lent. 2006. "Assessing the Performance of Business Unit Managers." Journal of Accounting Research 45(4): 667-697.

Gibbs, Michael, Kenneth Merchant, Wim Van der Stede, and Mark Vargus. 2009. "Performance Measure Properties and Incentive Plan Design.” Industrial Relations 48(2): 237-264.

Gibbons, Robert, and Michael Waldman. 1999. "Careers in Organizations: Theory and Evidence." In Handbook of Labor Economics, edited by Orley Ashenfelter and David Card. North Holland: Elsevier Science.

Heneman, Robert L., Gerold E. Ledford Jr., and Maria T. Gresham. 1999. "The Effects of Changes in the Nature of Work on Compensation." In Compensation in Organizations. Current Research and Practice, edited by Sara L. Rynes and Barry Gerhart. San Francisco: Jossey Bass.

Holmstrom, Bengt. 1979. "Moral Hazard and Observability.” The Bell Journal of Economics 10: 74-91.

Holmstrom, Bengt R., and Paul Milgrom. 1991. "Multitask Principal-Agent Analysis: Incentive Contracts, Asset Ownership and Job Design.” Journal of Law, Economics and Organization 7: 24-52.

Hwang, Yuhchang, David H. Erkens, and John H. Evans III. 2009. "Knowledge Sharing and Incentive Design in Production Environments: Theory and Evidence.” The Accounting Review 84(4): 11451170.

Heywood, John S., and Uwe Jirjahn. 2014. "Variable Pay, Industrial Relations and Foreign Ownership: 
Evidence from Germany.” Industrial Relations 52(3): 521-522.

Ittner, Christopher D., and David F. Larcker. 2002. "Determinants of Performance Measure Choices in Worker Incentive Plans.” Journal of Labor Economics 20(2): 58-90.

Jirjahn, Uwe. 2002. "The German Experience with Performance Pay." In Paying for Performance: An International Comparison, edited by Michelle Brown and John S. Heywood. Armonk, NY: M.E. Sharpe Publishers.

Jirjahn, Uwe, and Erik Poutsma. 2013. "The Use of Performance Appraisal Systems: Evidence from Dutch Establishment Data.” Industrial Relations 52(4): 801-827.

Kauhanen, Antti and Napari, Sami. 2012. "Performance Measurement and Incentive Plans." Industrial Relations: A Journal of Economy and Society 51(3): 645-669, 2012.

McAdams, Jerry L., and Elizabeth J. Hawk. 1994. Organizational Performance and Rewards: 663 Experiences in Making the Link. Phoenix: American Compensation Association.

Ortin-Angel, Pedro, and Vicente Salas-Fumas. 1998. “Agency-Theory and Internal Labor Market

Explanations of Bonus Payments: Empirical Evidence from Spanish Firms.” Journal of Economics and Management Strategy 7(4): 573-613.

Prendergast, Canice. 1999. "The Provision of Incentives in Firms.” Journal of Economic Literature 37(1): 763.

Raith, Michael. 2008. "Specific Knowledge and Performance Measurement." The RAND Journal of Economics 34(4): 1059-1079.

Zenger, Todd R. and C. R. Marshall. 2000. "Determinants of Incentive Intensity in Group-Based Rewards." Academy of Management Journal 43(2): 149-163. 


\section{Tables}

Table 1. Measure Properties and Incentive Intensity

\begin{tabular}{lc}
\hline Property & Incentive Intensity \\
\hline Noise & - \\
Controllable Risk & + \\
Impact on Firm Value & + \\
Distortion & - \\
Manipulability & - \\
\hline
\end{tabular}

Table 2. Measure Properties and Measurement Level

\begin{tabular}{lccc}
\hline \multirow{2}{*}{ Property } & \multicolumn{3}{c}{ Level } \\
\cline { 2 - 4 } Noise & Individual & Group & Plant/Firm \\
Controllable Risk & Low & Medium & High \\
Impact on Firm Value & High & Medium & Low \\
Distortion & Low & Medium & High \\
Manipulability & High & Medium & Low \\
\hline
\end{tabular}

Table 3. Properties of Categories of Measures

\begin{tabular}{lcccc}
\hline \multirow{2}{*}{ Property } & \multicolumn{4}{c}{ Categories } \\
\cline { 2 - 5 } & $\begin{array}{c}\text { Results Category } \\
\text { Productivity } \\
\text { Volume } \\
\text { Quality }\end{array}$ & $\begin{array}{c}\text { HRM Outcomes } \\
\text { Category } \\
\text { Absenteeism } \\
\text { Punctuality } \\
\text { Injuries }\end{array}$ & $\begin{array}{c}\text { Subjective } \\
\text { Category } \\
\text { Subjective } \\
\text { Evaluation } \\
\text { Customer } \\
\text { Satisfaction } \\
\text { External } \\
\text { Evaluation }\end{array}$ & $\begin{array}{c}\text { Financial } \\
\text { Category } \\
\text { Profitability } \\
\text { Cost savings }\end{array}$ \\
\hline Noise & Medium & Low & Low & High \\
Controllable Risk & Medium & High & Medium & Low \\
Impact on Firm Value & Medium & Low & Medium & High \\
Distortion & High & Medium & Low & Low \\
Manipulability & Medium & Low & High & Low \\
\hline NOn & & & &
\end{tabular}

NOTE: ${ }^{+}$Only used in plant or firm incentive programs 
Table 4. Use of Performance Measures

\begin{tabular}{|c|c|c|c|c|}
\hline $\begin{array}{l}\text { Performance } \\
\text { Measure }\end{array}$ & $\begin{array}{c}\text { Plants with any } \\
\text { PfP scheme }\end{array}$ & $\begin{array}{c}\text { Plants with } \\
\text { Individual PfP }\end{array}$ & $\begin{array}{l}\text { Plants with } \\
\text { Group PfP }\end{array}$ & $\begin{array}{c}\text { Plants with } \\
\text { Plant or Firm } \\
\text { PfP }\end{array}$ \\
\hline Productivity & $\begin{array}{c}380 \\
78.03 \%\end{array}$ & $\begin{array}{c}256 \\
77.81 \%\end{array}$ & $\begin{array}{c}159 \\
78.71 \%\end{array}$ & $\begin{array}{c}82 \\
52.90 \%\end{array}$ \\
\hline Volume & $\begin{array}{c}128 \\
26.28 \%\end{array}$ & $\begin{array}{c}67 \\
20.36 \%\end{array}$ & $\begin{array}{c}51 \\
25.25 \%\end{array}$ & $\begin{array}{c}35 \\
22.58 \%\end{array}$ \\
\hline Quality & $\begin{array}{c}197 \\
40.45 \%\end{array}$ & $\begin{array}{c}121 \\
36.78 \%\end{array}$ & $\begin{array}{c}76 \\
37.62 \%\end{array}$ & $\begin{array}{c}44 \\
28.39 \%\end{array}$ \\
\hline Absenteeism & $\begin{array}{c}101 \\
20.74 \%\end{array}$ & $\begin{array}{c}56 \\
17.02 \%\end{array}$ & $\begin{array}{c}45 \\
22.28 \%\end{array}$ & $\begin{array}{c}29 \\
18.71 \%\end{array}$ \\
\hline Punctuality & $\begin{array}{c}59 \\
12.11 \%\end{array}$ & $\begin{array}{c}38 \\
11.55 \%\end{array}$ & $\begin{array}{l}20 \\
9.90 \%\end{array}$ & $\begin{array}{c}15 \\
9.68 \%\end{array}$ \\
\hline Injuries & $\begin{array}{c}48 \\
9.86 \%\end{array}$ & $\begin{array}{c}21 \\
6.38 \%\end{array}$ & $\begin{array}{c}21 \\
10.40 \%\end{array}$ & $\begin{array}{c}23 \\
14.84 \%\end{array}$ \\
\hline Subjective & $\begin{array}{c}68 \\
13.96 \%\end{array}$ & $\begin{array}{c}45 \\
13.68 \%\end{array}$ & $\begin{array}{c}28 \\
13.82 \%\end{array}$ & $\begin{array}{c}17 \\
10.97 \%\end{array}$ \\
\hline Customer Satisfaction ${ }^{+}$ & $\begin{array}{c}20 \\
4.59 \%\end{array}$ & n.a. & n.a. & $\begin{array}{c}20 \\
12.90 \%\end{array}$ \\
\hline External Evaluation $^{+}$ & $\begin{array}{c}12 \\
2.75 \%\end{array}$ & n.a. & n.a. & $\begin{array}{c}12 \\
7.74 \%\end{array}$ \\
\hline Profitability $^{+}$ & $\begin{array}{c}54 \\
12.39 \%\end{array}$ & n.a. & n.a. & $\begin{array}{c}54 \\
34.84 \%\end{array}$ \\
\hline Cost Savings ${ }^{+}$ & $\begin{array}{l}15 \\
3.44 \%\end{array}$ & n.a. & n.a. & $\begin{array}{l}15 \\
9.68 \%\end{array}$ \\
\hline $\begin{array}{l}\text { Number of } \\
\text { Observations }\end{array}$ & 487 & 329 & 202 & 155 \\
\hline
\end{tabular}

NOTE: ${ }^{+}$Only used in plant or firm incentive programs 
Table 5. Number of Performance Measures

\begin{tabular}{|c|c|c|c|}
\hline $\begin{array}{l}\text { Number of Performance } \\
\text { Measures }\end{array}$ & $\begin{array}{c}\text { Plants with Individual } \\
\text { PfP }\end{array}$ & $\begin{array}{l}\text { Plants with } \\
\text { Group PfP }\end{array}$ & $\begin{array}{c}\text { Plants with } \\
\text { Plant or Firm } \\
\text { PfP }\end{array}$ \\
\hline 1 & $\begin{array}{c}186 \\
56.53 \%\end{array}$ & $\begin{array}{c}98 \\
48.51 \%\end{array}$ & $\begin{array}{c}80 \\
51.61 \%\end{array}$ \\
\hline 2 & $\begin{array}{c}74 \\
22.49 \%\end{array}$ & $\begin{array}{c}53 \\
26.24 \%\end{array}$ & $\begin{array}{c}33 \\
21.29 \%\end{array}$ \\
\hline 3 & $\begin{array}{c}40 \\
12.16 \%\end{array}$ & $\begin{array}{c}32 \\
15.84 \%\end{array}$ & $\begin{array}{c}16 \\
10.32 \%\end{array}$ \\
\hline 4 & $\begin{array}{c}14 \\
4.26 \%\end{array}$ & $\begin{array}{c}7 \\
3.47 \%\end{array}$ & $\begin{array}{c}13 \\
8.39 \%\end{array}$ \\
\hline 5 & $\begin{array}{c}5 \\
1.52 \%\end{array}$ & $\begin{array}{c}4 \\
1.98 \%\end{array}$ & $\begin{array}{c}3 \\
1.94 \%\end{array}$ \\
\hline 6 & $\begin{array}{c}1 \\
0.30 \%\end{array}$ & $\begin{array}{c}4 \\
1.98 \%\end{array}$ & $\begin{array}{c}3 \\
1.94 \%\end{array}$ \\
\hline 7 & $\begin{array}{c}9 \\
2.74 \%\end{array}$ & $\begin{array}{c}4 \\
1.98 \%\end{array}$ & $\begin{array}{c}0 \\
0.00 \%\end{array}$ \\
\hline 8 & n.a. & n.a. & $\begin{array}{c}1 \\
0.65 \%\end{array}$ \\
\hline 9 & n.a. & n.a. & $\begin{array}{c}1 \\
0.65 \%\end{array}$ \\
\hline 10 & n.a. & n.a. & $\begin{array}{c}5 \\
3.23 \%\end{array}$ \\
\hline 11 & n.a. & n.a. & $\begin{array}{c}0 \\
0.00 \%\end{array}$ \\
\hline Number of Observations & 329 & 202 & 155 \\
\hline
\end{tabular}


Table 6. Categories of Performance Measures

\begin{tabular}{|c|c|c|c|c|}
\hline Categories & $\begin{array}{l}\text { Plants with any } \\
\text { PfP scheme }\end{array}$ & $\begin{array}{c}\text { Plants with } \\
\text { Individual PfP }\end{array}$ & $\begin{array}{l}\text { Plants with } \\
\text { Group PfP }\end{array}$ & $\begin{array}{c}\text { Plants with } \\
\text { Plant or Firm } \\
\text { PfP }\end{array}$ \\
\hline Results Category & $\begin{array}{c}448 \\
91.99 \%\end{array}$ & $\begin{array}{c}303 \\
92.10 \%\end{array}$ & $\begin{array}{c}191 \\
94.55 \%\end{array}$ & $\begin{array}{c}101 \\
65.16 \%\end{array}$ \\
\hline $\begin{array}{l}\text { HRM Outcomes } \\
\text { Category }\end{array}$ & $\begin{array}{c}131 \\
26.90 \%\end{array}$ & $\begin{array}{c}73 \\
22.19 \%\end{array}$ & $\begin{array}{c}57 \\
28.22 \%\end{array}$ & $\begin{array}{c}44 \\
28.39 \%\end{array}$ \\
\hline Subjective Category & $\begin{array}{c}87 \\
17.86 \%\end{array}$ & $\begin{array}{c}45 \\
13.68 \%\end{array}$ & $\begin{array}{c}28 \\
13.86 \%\end{array}$ & $\begin{array}{c}39 \\
25.16 \%\end{array}$ \\
\hline Financial Category & $\begin{array}{c}59 \\
11.92 \%\end{array}$ & n.a. & n.a. & $\begin{array}{c}59 \\
38.06 \%\end{array}$ \\
\hline $\begin{array}{l}\text { Number of } \\
\text { Observations }\end{array}$ & 487 & 329 & 202 & 155 \\
\hline
\end{tabular}

Profitability and Cost Savings.

Table 7. Number of Categories

\begin{tabular}{lcccc}
\hline $\begin{array}{l}\text { Number of } \\
\text { Categories }\end{array}$ & $\begin{array}{c}\text { Plants with } \\
\text { any PfP } \\
\text { scheme }\end{array}$ & $\begin{array}{c}\text { Plants with } \\
\text { Individual } \\
\text { PfP }\end{array}$ & $\begin{array}{c}\text { Plants with } \\
\text { Group PfP }\end{array}$ & $\begin{array}{c}\text { Plants with } \\
\text { Plant or } \\
\text { Firm PfP }\end{array}$ \\
\hline One Category & 321 & 255 & 140 & 93 \\
& $65.91 \%$ & $77.51 \%$ & $69.31 \%$ & $60.00 \%$ \\
Two Categories & 108 & 56 & 50 & 44 \\
Three Categories & $22.18 \%$ & $17.02 \%$ & $24.75 \%$ & $28.39 \%$ \\
& 44 & 18 & 12 & 10 \\
Four Categories & 14 & $5.47 \%$ & $5.94 \%$ & $6.45 \%$ \\
& $2.87 \%$ & $n . a$. & 0.9. & 8 \\
$\begin{array}{l}\text { Number of } \\
\text { Observations }\end{array}$ & 487 & & & $5.16 \%$ \\
\hline
\end{tabular}


Table 8. Number of Performance Measures per Categories

\begin{tabular}{lcccc}
\hline Number of Measures & $\begin{array}{c}\text { Results } \\
\text { Category }\end{array}$ & $\begin{array}{c}\text { HRM } \\
\text { Outcomes } \\
\text { Category }\end{array}$ & $\begin{array}{c}\text { Subjective } \\
\text { Category }\end{array}$ & $\begin{array}{c}\text { Financial } \\
\text { Category }\end{array}$ \\
\hline 1 & 248 & 74 & 62 & 49 \\
& $55.36 \%$ & $56.49 \%$ & $83.78 \%$ & $83.05 \%$ \\
3 & 143 & 37 & 11 & 10 \\
3 & $31.92 \%$ & $28.24 \%$ & $14.86 \%$ & $16.95 \%$ \\
& 57 & 20 & 1 & n.a. \\
$\begin{array}{l}\text { Number of } \\
\text { Observations }\end{array}$ & $12.72 \%$ & $15.27 \%$ & $1.35 \%$ & 59 \\
\hline
\end{tabular}

NOTE: The Results Category includes Productivity, Volume and Quality; the HRM Outcomes Category includes Absenteeism, Punctuality and Injuries; the Subjective Category includes Subjective Evaluation, Customer Satisfaction and External Evaluation; the Financial Category includes Profitability and Cost Savings. 
Table 9. Determinants of PfP Intensity, OLS Regressions

\begin{tabular}{|c|c|c|c|c|c|}
\hline Variable & Model 1 & Model 2 & Model 3 & Model 4 & Model 5 \\
\hline Constant & $\begin{array}{c}14.453 * * \\
(6.975)\end{array}$ & $\begin{array}{l}16.838^{*} \\
(1.577)\end{array}$ & $\begin{array}{l}12.438 * \\
(6.994)\end{array}$ & $\begin{array}{l}11.889 \\
(7.310)\end{array}$ & $\begin{array}{l}10.119 \\
(7.386)\end{array}$ \\
\hline Individual PfP & $\begin{array}{c}4.723 * * * \\
(1.701)\end{array}$ & - & - & $\begin{array}{c}5.578 * * * \\
(1.800)\end{array}$ & $\begin{array}{c}4.873 * * * \\
(1.701)\end{array}$ \\
\hline Group PfP & $\begin{array}{c}5.482 * * * \\
(1.589)\end{array}$ & - & - & $\begin{array}{c}6.494 * * * \\
(1.950)\end{array}$ & $\begin{array}{c}5.307 * * * \\
(1.660)\end{array}$ \\
\hline $\begin{array}{l}\text { Plant or Firm } \\
\text { PfP }\end{array}$ & $\begin{array}{l}-1.220 \\
(1.670)\end{array}$ & - & - & $\begin{array}{c}1.393 \\
(2.071)\end{array}$ & $\begin{array}{c}.226 \\
(2.067)\end{array}$ \\
\hline Productivity & - & $\begin{array}{l}2.888 * \\
(1.577)\end{array}$ & - & $\begin{array}{c}1.430 \\
(1.559)\end{array}$ & - \\
\hline Volume & - & $\begin{array}{c}.447 \\
(1.541)\end{array}$ & - & $\begin{array}{c}0.310 \\
(1.557)\end{array}$ & - \\
\hline Quality & - & $\begin{array}{c}2.250 \\
(1.563)\end{array}$ & - & $\begin{array}{c}2.044 \\
(1.542)\end{array}$ & - \\
\hline Absenteeism & - & $\begin{array}{c}-3.403 * * \\
(1.640)\end{array}$ & - & $\begin{array}{c}-3.546 * * \\
(1.709)\end{array}$ & - \\
\hline Punctuality & - & $\begin{array}{c}3.093 \\
(2.382)\end{array}$ & - & $\begin{array}{c}3.476 \\
(2.388)\end{array}$ & - \\
\hline Injuries & - & $\begin{array}{c}-5.185^{* * *} \\
(1.191)\end{array}$ & - & $\begin{array}{c}-6.196 * * * \\
(1.969)\end{array}$ & - \\
\hline Subjective & - & $\begin{array}{l}-1.389 \\
(2.013)\end{array}$ & - & $\begin{array}{c}-3.776 * * \\
(1.907)\end{array}$ & - \\
\hline $\begin{array}{l}\text { Customer } \\
\text { Satisfaction }\end{array}$ & - & $\begin{array}{c}-.307 \\
(3.591)\end{array}$ & - & $\begin{array}{c}.829 \\
(3.980)\end{array}$ & - \\
\hline $\begin{array}{l}\text { External } \\
\text { Evaluation }\end{array}$ & - & $\begin{array}{c}-10.532 * * * \\
(3.993)\end{array}$ & - & $\begin{array}{c}-10.699 * * * \\
(3.254)\end{array}$ & - \\
\hline Profitability & - & $\begin{array}{c}-3.386 * * \\
(1.670)\end{array}$ & - & $\begin{array}{l}-3.685^{*} \\
(2.120)\end{array}$ & - \\
\hline Cost Savings & - & $\begin{array}{c}15.303 * * \\
(6.639)\end{array}$ & - & $\begin{array}{c}16.304 * * \\
(6.923)\end{array}$ & - \\
\hline Results Category & - & - & $\begin{array}{c}8.132 * * * \\
(2.040)\end{array}$ & - & $\begin{array}{l}4.910 * * \\
(1.701)\end{array}$ \\
\hline $\begin{array}{l}\text { HRM Outcomes } \\
\text { Category } \\
\text { Subjective } \\
\text { Category }\end{array}$ & - & - & $\begin{array}{c}-1.686 \\
(1.662) \\
-.605 \\
(1.811)\end{array}$ & - & $\begin{array}{c}-1.874 \\
(1.680) \\
-2.077 \\
(1.786)\end{array}$ \\
\hline $\begin{array}{l}\text { Financial } \\
\text { Category }\end{array}$ & - & - & $\begin{array}{l}-1.199 \\
(2.082)\end{array}$ & - & $\begin{array}{c}-.412 \\
(2.456)\end{array}$ \\
\hline $\begin{array}{c}\text { Controls } \\
\mathrm{R}^{2} \\
\mathrm{~F}\end{array}$ & $\begin{array}{c}\text { Yes } \\
0.06 \\
7.80 * * *\end{array}$ & $\begin{array}{c}\text { Yes } \\
0.11 \\
4.67 * * *\end{array}$ & $\begin{array}{c}\text { Yes } \\
0.06 \\
5.41 * * *\end{array}$ & $\begin{array}{c}\text { Yes } \\
0.14 \\
5.50 * * *\end{array}$ & $\begin{array}{c}\text { Yes } \\
0.08 \\
6.37 * * *\end{array}$ \\
\hline $\mathrm{N}$ & 456 & 394 & 449 & 394 & 447 \\
\hline
\end{tabular}

NOTES:

$* * * \mathrm{p}<0.01, * * \mathrm{p}<0.05, * \mathrm{p}<0.10$.

The Results Category includes Productivity, Volume and Quality; the HRM Outcomes Category includes Absenteeism, Punctuality and Injuries; the Subjective Category includes Subjective Evaluation, Customer Satisfaction and External Evaluation; the Financial Category includes Profitability and Cost Savings. 
Table 10. Determinants of PfP Intensity by Scheme, OLS Regressions

\begin{tabular}{|c|c|c|c|c|c|c|}
\hline \multirow[b]{2}{*}{ Variable } & \multicolumn{2}{|c|}{ Individual PfP } & \multicolumn{2}{|c|}{ Group PfP } & \multicolumn{2}{|c|}{ Plant or Firm PfP } \\
\hline & Model 1 & Model 2 & Model 3 & Model 4 & Model 5 & Model 6 \\
\hline Constant & $\begin{array}{c}9.620 \\
(7.607)\end{array}$ & $\begin{array}{c}9.272 \\
(7.419)\end{array}$ & $\begin{array}{c}30.804 * * * \\
(10.103)\end{array}$ & $\begin{array}{c}30.804 * * \\
(12.118)\end{array}$ & $\begin{array}{c}9.913 \\
(9.219)\end{array}$ & $\begin{array}{c}4.562 \\
(9.194)\end{array}$ \\
\hline Productivity & $\begin{array}{l}3.261 * \\
(1.907)\end{array}$ & - & $\begin{array}{l}-1.428 \\
(2.372)\end{array}$ & - & $\begin{array}{c}-.175 \\
(2.877)\end{array}$ & - \\
\hline Volume & $\begin{array}{c}3.383 \\
(2.620)\end{array}$ & - & $\begin{array}{c}.116 \\
(2.244)\end{array}$ & - & $\begin{array}{c}.090 \\
(2.378)\end{array}$ & - \\
\hline Quality & $\begin{array}{c}2.714 \\
(1.701)\end{array}$ & - & $\begin{array}{c}2.892 \\
(2.160)\end{array}$ & - & $\begin{array}{c}2.467 \\
(3.688)\end{array}$ & - \\
\hline Absenteeism & $\begin{array}{c}-.574 \\
(2.578)\end{array}$ & - & $\begin{array}{c}-.390 \\
(3.083)\end{array}$ & - & $\begin{array}{l}-4.565^{*} \\
(2.727)\end{array}$ & - \\
\hline Punctuality & $\begin{array}{c}2.857 \\
(3.412)\end{array}$ & - & $\begin{array}{l}9.142 * \\
(4.707)\end{array}$ & - & $\begin{array}{c}2.252 \\
(3.148)\end{array}$ & - \\
\hline Injuries & $\begin{array}{c}-7.349 * * \\
(2.837)\end{array}$ & - & $\begin{array}{c}-6.903 * * \\
(3.395)\end{array}$ & - & $\begin{array}{l}-2.143 \\
(2.702)\end{array}$ & - \\
\hline Subjective & $\begin{array}{c}-4.360 * * \\
(2.085)\end{array}$ & - & $\begin{array}{l}-3.809 \\
(3.207)\end{array}$ & - & $\begin{array}{c}-.083 \\
(3.334)\end{array}$ & - \\
\hline $\begin{array}{l}\text { Customer } \\
\text { Satisfaction }\end{array}$ & - & - & - & - & $\begin{array}{l}-3.435 \\
(3.496)\end{array}$ & - \\
\hline $\begin{array}{l}\text { External } \\
\text { Evaluation }\end{array}$ & - & - & - & - & $\begin{array}{l}-3.553 \\
(4.349)\end{array}$ & - \\
\hline Profitability & - & - & - & - & $\begin{array}{l}-3.709 * \\
(2.213)\end{array}$ & - \\
\hline Cost Savings & - & - & - & - & $\begin{array}{c}11.999 * * \\
(6.479)\end{array}$ & - \\
\hline $\begin{array}{l}\text { Results } \\
\text { Category } \\
\text { HRM Outcomes } \\
\text { Category } \\
\text { Subjective } \\
\text { Category }\end{array}$ & $\begin{array}{l}- \\
-\end{array}$ & $\begin{array}{c}4.741 * * * \\
(1.682) \\
-.284 \\
(2.177) \\
-3.616 * * \\
(1.739)\end{array}$ & $\begin{array}{l}- \\
- \\
-\end{array}$ & $\begin{array}{c}.234 \\
(5.219) \\
-.628 \\
(2.651) \\
-1.985 \\
(2.749)\end{array}$ & $\begin{array}{l}- \\
-\end{array}$ & $\begin{array}{c}3.973 * \\
(2.307) \\
-3.471 * \\
(1.990) \\
1.050 \\
(2.227)\end{array}$ \\
\hline $\begin{array}{l}\text { Financial } \\
\text { Category }\end{array}$ & - & - & - & - & - & $\begin{array}{c}-.491 \\
(2.183) \\
\end{array}$ \\
\hline $\begin{array}{c}\text { Controls } \\
\mathrm{R}^{2} \\
\mathrm{~F}\end{array}$ & $\begin{array}{c}\text { Yes } \\
0.10 \\
4.95^{* * *}\end{array}$ & $\begin{array}{c}\text { Yes } \\
0.07 \\
7.00 * * *\end{array}$ & $\begin{array}{c}\text { Yes } \\
0.08 \\
1.91 * *\end{array}$ & $\begin{array}{c}\text { Yes } \\
0.03 \\
1.07\end{array}$ & $\begin{array}{c}\text { Yes } \\
0.13 \\
1.27\end{array}$ & $\begin{array}{c}\text { Yes } \\
0.08 \\
2.00 *\end{array}$ \\
\hline $\mathrm{N}$ & 292 & 292 & 181 & 181 & 137 & 137 \\
\hline
\end{tabular}

NOTES:

$* *$ * $p<0.01, * * \mathrm{p}<0.05, * \mathrm{p}<0.10$

The Results Category includes Productivity, Volume and Quality; the HRM Outcomes Category includes Absenteeism, Punctuality and Injuries; the Subjective Category includes Subjective Evaluation, Customer Satisfaction and External Evaluation; the Financial Category includes Profitability and Cost Savings. 